\section{Coming and Going in Loops: Participatory Modelling of a System with All its Complexity}

\author{
Dmitry Brychkov $(\mathbb{D}$, Christine Domegan $(\mathbb{D}$, and Patricia McHugh
}

\begin{abstract}
Social marketing is currently involved in pursuing several important theoretical and methodological goals pertaining to wide-scale behavior change. The lack of complex system understanding via highly participatory processes and feedback loops is a major impediment for systemic behavior change. The purpose of this paper is to show how the implementation of participatory modelling to explore networks of feedback loops can empower social marketing in capturing system complexity. As a case study, a group of system stakeholders qualitatively modelled a cycling system in a city setting to uncover the system's core behavioral dynamics. This participatory modelling process revealed that the interactions within and between three feedback loops were mainly responsible for the cycling system issues. These feedback loops were: (a) output-based and autocratic decision-making, (b) an abundance of conflicted interests and (c) the reinforcement of a car-dominant paradigm in people's minds. The paper contributes to understanding the potential of participatory modelling for multi-level behavior change.
\end{abstract}

\title{
Keywords
}

complexity, cycling, dynamics, feedback loop, participatory modelling, social marketing, system

\section{Introduction}

"...one is thus brought to make a come and go in loop to gather the knowledge of the whole and its parts." Edgar Morin (2006, p. 6, emphasis added).

Both the natural and social sciences engage in the operationalization of various concepts, though, for social sciences, this task is more difficult because of the need to deal with many uncontrolled variables (Diamond 1987). In the same vein, Wooliscroft $(2016$, p. 8) stresses that "rocket scientists deal with constants, whereas macromarketers deal with noise, randomness - people, and people interacting with other people to produce real chaos." Noise, randomness and chaos are immanent features of systems-induced complexity.

Systems-induced complexity has been on the radar of natural and social sciences (Byrne and Callaghan 2014; Jackson 2019; Morin 2006). These sciences are mostly preoccupied with what is known as restricted complexity. The latter analyzes complexity as a phenomenon, which emerges from the interaction of simple components and agents, relying on simulations in the form of non-linear equations or agent-based models (Jackson 2019). In this type of complexity, structure is micro-emergent; it does not possess an independent reality and has no causal powers of its own (Jackson 2019). Restricted complexity "ignores the fact that individuals are themselves complex systems, and certainly more complex in every way than the agents in agent-based simulations" (Byrne and Callaghan 2014, p. 41).
The social world entails general complexity (Morin 2006). According to Byrne and Callaghan (2014), this type of complexity is about "nested and interpenetrating complex social systems beyond individuals, although of course with individuals as elements in those systems" (p. 41, emphasis added), "with causal powers running in all directions" (p. 45). This makes the complexity of the social world much harder to grasp by existing social theories.

Macromarketing and social marketing try to manage the general complexity of social reality by addressing nested and interdepending complex social (marketing) systems, as well as multiple related topics: system non-linearity (Carvalho and Mazzon 2020; Kennedy 2020), hierarchies and intersectionality (Steinfield and Holt 2020), importance of initial conditions (Layton 2015), attenuating and cumulative effects (Kadirov 2018), roles of structure and agency (Domegan et al. 2019), emergence (Layton 2015), path dependence (Layton and Duffy 2018), evolution and transformation (Conejo and Wooliscroft 2015; Layton 2015; Layton and Domegan 2021; Previte and Robertson 2019). However, these endeavors come at a cost. When macro and social marketers are confronted with the reality of the social world, researchers and practitioners reduce complexity "in order to maintain the meaningfulness of

Marketing Discipline, J.E. Cairnes School of Business and Economics, NUI Galway, Galway, Ireland

\section{Corresponding Author:}

Dmitry Brychkov, Marketing Discipline, J.E. Cairnes School of Business and Economics, NUI Galway, H9I CF50, Ireland.

Email: dzmitry.brychkov@nuigalway.ie 
both collective and individual action, the view of environment, and desired outcomes" (Kadirov 2018, p. 278). They often fail to grasp complexity of systems or, in the parlance of complexity theory, to cross a deep ontological and epistemological gap between restricted and general complexity. In general, scientists are more comfortable with traditional linear thinking, which does not require the analysis of unpredictable feedback loops (Wooliscroft 2020).

Social marketing is not an exclusion here. The capacity of social marketing to address upstream actors, complex behavioral responses, macro-level and intricate dynamic causality of problems is questioned (Carvalho and Mazzon 2020; Truong 2017) due to the discipline's issues with understanding systems (Anibaldi, Carins, and Rundle-Thiele 2020), which inevitably leads to unintended consequences (Corner and Randall 2011; Kennedy 2020). To address these issues, social marketing has been incorporating systemic approaches in theory, methodology and practice to deal with a shift from individualistic to systemic behavioral change (Kennedy 2020; Saunders, Graham, and Truong 2019). Besides, there is a need to change mindsets accordingly to support new ways of communication and collaboration at the collective and systems levels (Jackson 2019). The lack of such new mindsets poses a large challenge for social marketing as it creates a gap between intentions and their realization. Social marketing only learns how to deal with the challenge of addressing complex social systems "in order to plan strategically for their improvement" (Kapitan 2020, p. 29). It is considered to be a matter of future research for social marketing to capture more complexity of social systems, including their power dynamics, and to explore the causal links in such systems (Kubacki, Siemieniako, and Brennan 2020), without "breaking down wholes and systems to dyads" of linear interactions and causal chains (Wooliscroft 2020, p. 17).

The purpose of this paper is to show how the implementation of participatory modelling, including feedback loops, can empower social marketing to plan and execute multi-level systemic behavior change that captures more general complexity. It is achieved via a case study collaborative application of modelling for the behavioral analysis of a complex system, that is a cycling system in a city setting. Therefore, the paper aims are to:

1) model the behavioral dynamics of a complex mobility and social system with the help of participatory modelling; and

2) understand how this modelling could be advantageous for the social marketing systems improvement.

The paper has the following structure. The initial section conceptualizes the social marketing shift from individual to systems change. The next two sections explain the essence of the methodology, i.e. participatory modelling in its qualitative form. These two sections: (a) detail the meaning of "participatory", which makes use of collective intelligence, that is, systemic stakeholder involvement from problem definition to circular causality modelling and identification of the system change areas and (b) clarify the second element, "qualitative", by explaining meaning, logic and rigor of qualitative modelling. These methodological foundations are also related to the context of the research, i.e. a study of the operation of a complex social and mobility system. In the findings section, the paper visualizes a complex mobility system via a network of behavioral dynamic interactions, uncovers the core behavioral dynamics and highlights the central feedback loops of the dynamics. A cycling system map (specifically its core dynamics parts), is also presented which acts as a consultation-based, socialized and visualized model, accompanied by the narratives telling the "stories" of the separate system fragments and the whole system. The discussion section sums up the benefits of participatory modelling and feedback loops for wide-scale behavior change and macromarketing. The paper concludes with the explanation of the limitations of this modelling for systems social marketing interventions.

\section{Social Marketing Shift to Wide-Scale Change, Understanding Complexity and Multi-Stakeholder Systemic Participation}

Social marketing is currently involved in pursuing several important theoretical and methodological goals among which the shift from reliance on exclusively micro-level behavioral change to wide-scale transformation of a problem is the most ambitious objective (Rundle-Thiele et al. 2019). There is no dichotomy between individual and collective behavioral change, as the link between the two represents a continuum of macro-micro-macro everyday feedback dynamics between stakeholders (Domegan et al. 2019; Smith 2000).

The necessity of this shift from individual behavior change, operationally focused thinking and one-time interventions to a sustainable and holistic strategy, based on systems theory, strategic planning, network analysis, relationship marketing and partnership formation, is stressed in various publications (Dibb 2014; French and Gordon 2019; Hastings and Domegan 2018; Kennedy 2017). A similar trend is evident in macromarketing, with its endeavors to reverse "the dominant micro-macro logic, which is conventionally based on an assumption that micromotives, i.e. rational individual decisions, cause (un)desirable macro consequences" (Kadirov 2018, p. 286). Complexity theory posits likewise by branding the logic of emergence from individual actions as microdeterminism or micro fallacy (Byrne and Callaghan 2014).

In a similar vein, Rundle-Thiele et al. (2019, p. 160) advocate the need to "deliver frameworks that extend focus beyond individuals to all citizens, and apply new evaluation approaches that assess individual and structural changes." To achieve this, they formulated ten Social Marketing Theory Development Goals, in which they, among various actions, substantiate the development of advanced modelling techniques for complexity understanding, involving system-wide stakeholder participation. The shift to wide-scale change and efforts to grasp system complexity are evident in different systemic 
approaches in social marketing (Table 1). However, the way these approaches try to understand system complexity differs on two important criteria.

First, understanding system complexity stipulates the analysis of its circular causality, which involves the concept of feedback. The latter means that system-forming elements exist in causal relationships, which are "organized" as networks of interconnected feedback loops. Causality circulates along these loops, like electrons travelling in circular orbits, so each system element receives a feedback (sometimes delayed) of causal influence from other elements in a loop. Second, understanding system complexity requires active participation and learning of system-wide stakeholders, not just expert stakeholders, in grasping this system complexity by various methods of system modelling. Table 1 shows the difference between systemic social marketing approaches with respect to both criteria.

Table 1 highlights that systemic social marketing approaches understand complexity in different ways, while the use of feedback loops and participation of system-wide stakeholders in system complexity understanding is not common or not

Table I. Complexity Understanding via Systemic Social Marketing Approaches.

\begin{tabular}{|c|c|c|}
\hline Approach & $\begin{array}{l}\text { Understanding } \\
\text { circular causality of } \\
\text { systems }\end{array}$ & $\begin{array}{l}\text { Participation of } \\
\text { system-wide } \\
\text { stakeholders }\end{array}$ \\
\hline $\begin{array}{l}\text { Community-based } \\
\text { social marketing } \\
\text { (McKenzie-Mohr } \\
\text { 2011) }\end{array}$ & $\begin{array}{l}\text { Systemic } \\
\text { identification of } \\
\text { issue barriers; }\end{array}$ & $\begin{array}{l}\text { Building community } \\
\text { support; }\end{array}$ \\
\hline $\begin{array}{l}\text { Macro-social } \\
\text { marketing } \\
\text { (Kennedy 2020) }\end{array}$ & $\begin{array}{l}\text { Multi-disciplinary } \\
\text { understanding of } \\
\text { system } \\
\text { complexity; }\end{array}$ & $\begin{array}{l}\text { Altering } \\
\text { problem-perpetuating } \\
\text { institutional norms of } \\
\text { all system actors; }\end{array}$ \\
\hline $\begin{array}{l}\text { Systems-thinking } \\
\text { social marketing } \\
\text { (Domegan et al. } \\
\text { 2016, 2019, 2020; } \\
\text { McHugh, } \\
\text { Domegan, and } \\
\text { Duane 2018) }\end{array}$ & $\begin{array}{l}\text { Use of feedback } \\
\text { loops and value } \\
\text { exchange analysis; }\end{array}$ & $\begin{array}{l}\text { Participation of } \\
\text { system-wide } \\
\text { stakeholders in system } \\
\text { complexity } \\
\text { understanding; }\end{array}$ \\
\hline $\begin{array}{l}\text { Community-based } \\
\text { social marketing } \\
\text { and system } \\
\text { dynamics } \\
\text { frameworks } \\
\text { (Biroscak et al. } \\
\text { 2019; Bryant et al. } \\
\text { 2014; Hovmand } \\
\text { 2014) }\end{array}$ & $\begin{array}{l}\text { Use of feedback } \\
\text { loops within } \\
\text { system dynamics } \\
\text { modelling; }\end{array}$ & $\begin{array}{l}\text { Use of group model } \\
\text { building; }\end{array}$ \\
\hline $\begin{array}{l}\text { Strategic social } \\
\text { marketing (French } \\
\text { and Gordon 2019) }\end{array}$ & $\begin{array}{l}\text { Incorporation of } \\
\text { systems thinking; }\end{array}$ & $\begin{array}{l}\text { Incorporation of } \\
\text { participatory methods; }\end{array}$ \\
\hline $\begin{array}{l}\text { Behavioral ecological } \\
\text { systems approach } \\
\text { (Brennan, Previte, } \\
\text { and Fry 2016) }\end{array}$ & $\begin{array}{l}\text { Adapted } \\
\text { Bronfenbrenner's } \\
\text { ecological } \\
\text { systems model; }\end{array}$ & $\begin{array}{l}\text { Analysis of various } \\
\text { societal levels of } \\
\text { multiple stakeholders; }\end{array}$ \\
\hline
\end{tabular}

deliberately pronounced. The lack of focus on circular causality and on system-wide stakeholder participation in complexity understanding acts as a major impediment for systemic change in social marketing.

\section{Participatory Modelling for Wide-Scale Behavior Change}

Involving multiple stakeholders in modelling a system is not unusual. For instance, system dynamics enables a collective participatory way of developing a system model, known as group model building, since "effective learning from models occurs best, and perhaps only, when the decision-makers participate actively in the development of the model" (Sterman 2000, p. 36). Group model building is a highly participatory method for involving people in a modelling process and decisionmaking in response to problem situations (Hovmand 2014). Under this process, system-wide stakeholders, (gathered in working groups), with knowledge of a complex problem system, consensually originate a dynamic model of this system (Figure 1).

During participatory modelling, members of a modelling team explore circular causal relationships between system components via the application of specific concepts (e.g., a concept of feedback) and tools, like drawing causal loop diagrams (CLDs) to map feedback dynamics (Rees et al. 2017; Sterman 2000). The essence of gathering stakeholder groups is to exchange mental models between their members in order to unravel and communicate important problem-affecting feedback loops, which include key elements and causal links between these elements, thus hypothesizing about system feedback behavior (Hovmand 2014). The participants of these groups try, via shared understanding and available expertise, to obtain tangible representation of dependencies across various system dimensions; they are also empowered with an ability to freely and iteratively modify their representation (Black and Andersen 2012). This person-empowering, active and dynamic complexity-modelling character makes participatory modelling approaches distinct from other group-based methodological tools.

\section{Meaning, Logic and Rigor of Qualitative Modelling}

We share the position of Wolstenholme (1999) that the need in quantification in system modelling is subject to analysis objectives, employed methodology and the addressed audience. This paper draws a qualitative system model (map) with many elements resistant to quantification, while the target audience(s) may include various system stakeholders often without basic knowledge of system modelling. Therefore, the choice of qualitative system modelling is justified. Likewise, systems scientist Peter Senge, in his book, The Fifth Discipline, "dropped any pretense to rigorous modelling and promoted a qualitative form of SD” [system dynamics] (Jackson 2019, p. 233). 


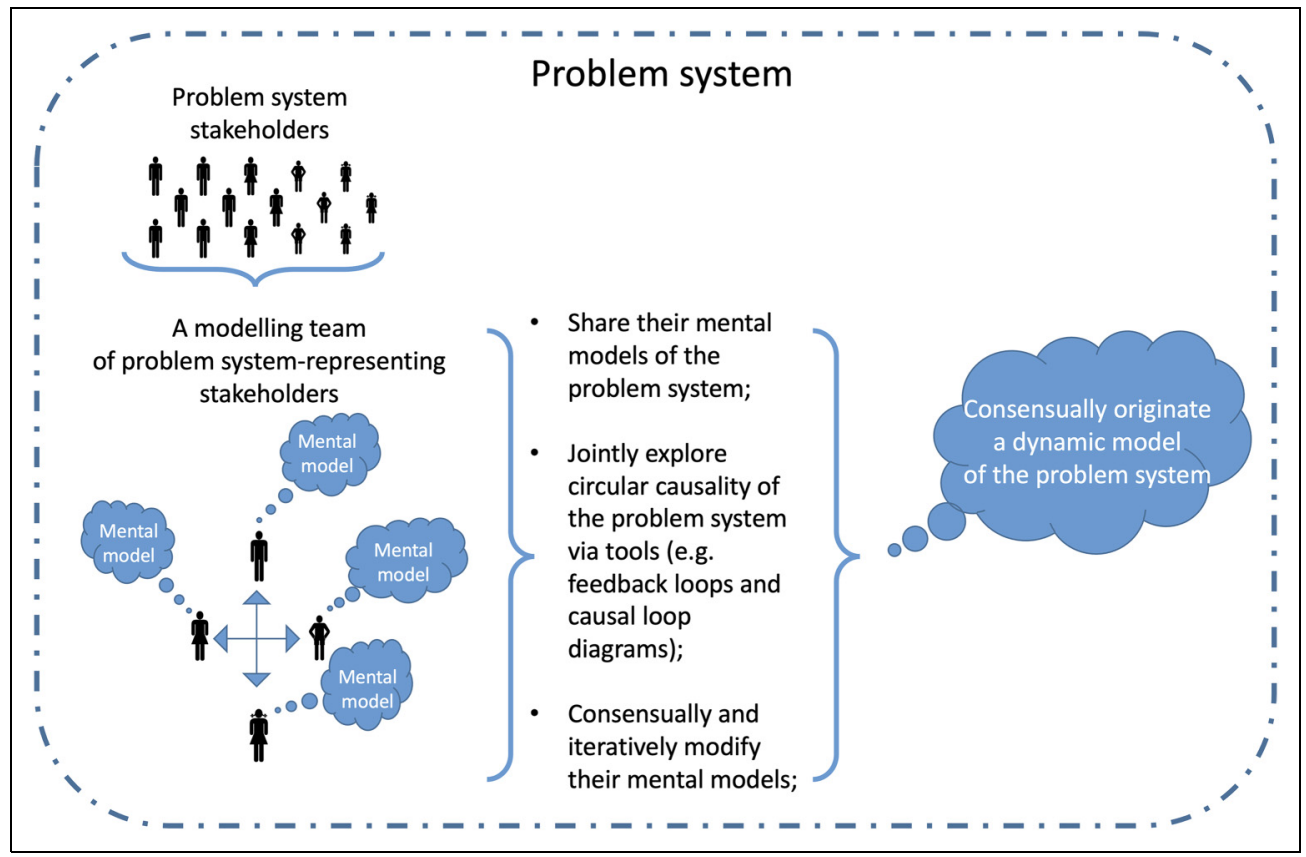

Figure I. Participatory modelling of a problem system.

System modelling, for example via system dynamics, can be used both qualitatively and quantitatively. Qualitative system dynamics can be defined as a method for the analysis of the system behavior with the help of a conceptual (mental) model (Coyle 2009; Wolstenholme 1999). A model here simply means "a set of assumptions describing a problematic situation" (Lane 2000, p. 241). A conceptual (mental) model derives from stand-alone causal loop diagrams (Kunc 2017), as well as inferences from them. "Stand-alone" means that the depiction of a single causal loop diagram is sufficient for understanding a system's behavior. A causal loop diagram captures how elements in the system are interrelated by depicting cause-and-effect linkages, including directions and polarity of causal relationships between these elements, thus effectively portraying the feedback loop structure of a system (Sterman 2000). These linkages are not quantified via any equations. Causal loop diagrams provide a broad representation of a control feedback structure of a system. Drawing such diagrams can be used as a conceptualization tool which facilitates a mental inference of a system's behavior and provides insights for decision-makers (Kunc 2017; Lane 2000). The need in qualitative forms of model-building is often dictated by the existence of a large number of soft, hard-to-measure, elements in a system, as well as by reliance on textual data obtained from interviews and theories.

In contrast to qualitative system dynamics, quantitative system dynamics can be defined as a method for the analysis of the time-dependent behavior of the system. It uses a five-step modelling process, which includes dynamic hypothesis and the development of a formal computer simulation model with the help of regressions, reference modes, and quantifiable variables (Coyle 2009; Kunc 2017; Sterman 2000). As such, a computer simulation model mainly derives from a stock-and-flow diagram and a set of simulation equations that quantify linkages between different types of variables. The main objectives of quantitative system dynamics modelling include the elimination of inconsistencies in understanding of general behavior the system and the empirical testing of hypothesis about system behavior and all causal mechanisms.

Qualitative modelling is criticized for its weakness to infer complex system behavior due to the absence of simulations (Morecroft 1982). This critique is not fully justified, as qualitative modelling is also good for understanding behavioral dynamics and especially for understanding the general and undesirable behavior of the system to provide insights about the system for policy-makers and improve thinking about the structure of the problem (Kunc 2017; Lane 2000). Its value can be increased by active involvement and empowerment of different system-representing stakeholders in extracting rich qualitative data about the system and its complexity. These stakeholders dedicate time to analyze the system elements and their interactions, as well as to structure, categorize and debate these interacting elements with a considerable level of attention. These system-wide modelers integrate the system elements into system feedback loops and networks (represented as maps) in a meticulous way by telling specific stories or narratives of each loop and of the whole system. Gathered in groups, they further socialize the originated stories and system maps in a wide multi-stakeholder environment to cater for possible mistakes and discrepancies of their system visualizations. They perform these activities in an iterative manner so the products they derive become dynamic tools rather than static objects of analysis. This constant iteration, continuous polishing of modelling skills, collective learning and adherence 
to strict procedure of qualitative system modelling is instrumental in providing research rigor.

\section{Research Context}

The domain of transportation, which closely links to urbanism, urban planning, energy saving, sustainability and health, remains paramount for the development of human civilization. Cycling, which is a sustainable transport mode and the subsystem of the transportation system, is at the crossroads of these domains. A cycling system acts here as a localized subsystem within the bigger transportation and urban planning systems and constantly interacts with other transport and urban sub-systems, for instance, with the motorized transport, public transportation or housing sub-systems.

Being a complex behavioral response to mobility and sustainability issues, cycling is currently underdeveloped in Ireland, which poses a serious problem to human prosperity, well-being and health (Carroll et al. 2020; Hynes and Seoighthe 2018). The Galway transportation issue, (Galway is a small city on the west coast of Ireland with a population of around 80,000 people), may be defined as a "zone of complexity" as such zones are commonly characterized by both high uncertainty and strong social conflict (Patton 2011). The existing transportation system in Galway is marked by excessive car dependence, underdevelopment of public and active transport modes (incl. cycling), lack of intra-urban connectivity (e.g., between eastern and western suburban areas), large travel times and regular traffic congestion problems. These problems are instigated by deficient urban planning practices, which are characterized by large city sprawl, low-density suburbs, excessive city/rural travels, and detached local communities (Hynes 2017; Hynes and Seoighthe 2018; Lawson, McMorrow, and Ghosh 2013; Rau, Hynes, and Heisserer 2016).

\section{Methodology}

\section{Research Design and Process}

The research design consists of four phases (Figure 2a). Phase 1 includes systemic stakeholder analysis, enabled by (a) a literature review, (b) content assessment with the help of Leximancer software (https://www.leximancer.com), and (c) purposive/ snowball sampling. Systemic stakeholder analysis results in establishing a system-modelling group (a modelling group) and helps to demarcate the localized system boundaries. Phase 2 involves a system barrier/enabler analysis, assisted by a cycling-related literature review, as well as group and one-to-one interviews. This phase helps to define the nature of the problem represented by its key forces. Phase 3 leads to the cycling system map origination via group-based system modelling sessions. This phase aims to understand, via a series of single and system feedback loop narratives, the central behavioral dynamics in the system. Finally, Phase 4 verifies and corrects, if necessary, the understanding of system's behavioral dynamics when the cycling system map is socialized via key informant interviews and further modelling group-based consultations. It also generates Change Areas, i.e. the areas of multi-level intervention to address system deficiencies in the optimal way. During Phases 3 and 4, the generation of the system map is assisted by the use of Kumu software (https://kumu.io), which is used to draw all corresponding individual feedback loops and to combine them in a coherent map. The choice of Kumu is determined by its visually rich capacity to draw causal loop diagrams, a user-friendly interface and multiple options for presenting system elements and fragments. Table 2 indicates relevant sample sizes, data collection agents, outcomes and timeframes for each specific activity/ method in all phases.

The methodology fits well with and further develops the typical social marketing planning process, specifically in the domains of problem and stakeholder analyses (Figure 2b). Methodologically, the typical social marketing planning process implies analyses of both macro- and microenvironments, including "political/legal, economic, social and technological" forces, as well as "careful monitoring of these forces" (Hastings 2007, p. 53), which is in line with Bronfenbrenner's ecological systems theory (Brennan, Previte, and Fry 2016). However, the suggested multiphase research design dedicates, optimizes and streamlines the problem and stakeholder analyses by involving systemic stakeholder analysis and by modelling complex causality.

\section{Phase I: Systemic Stakeholder/Boundary Analysis and Modelling Group Formation}

Systemic stakeholder analysis is needed to define a problem system in question and to establish a modelling group, a main driving task force of the system modelling process. To do this, the research used non-probability purposive sampling where sample units were selected by virtue of their relevance to several criteria: knowledge in the Galway cycling system, affiliation to any of the system's key stakeholder groups, and readiness to participate in group-based modelling sessions in order to be empowered with system modelling skills.

By defining a problem system, systemic stakeholder analysis also implies demarcating the boundary of a problem system. The systemic boundary analysis in this research meant the inclusion of all stakeholders of the Galway cycling system into consideration. A stakeholder is defined in a manner analogous to Freeman's broad definition of a stakeholder: “....any group or individual who can affect or is affected by the achievement of the organization's objectives" (Freeman 1984, p. 46), which here may be paraphrased to mean any group or individual who can affect or is affected by the Galway cycling system and its operation.

Initially, the systemic stakeholder analysis relied on a literature review, which included (a) policy papers, reports, press releases, official plans and guidelines, issued by national / local governments and quasi-autonomous NGOs, often in collaboration with business entities and experts; (b) academic 


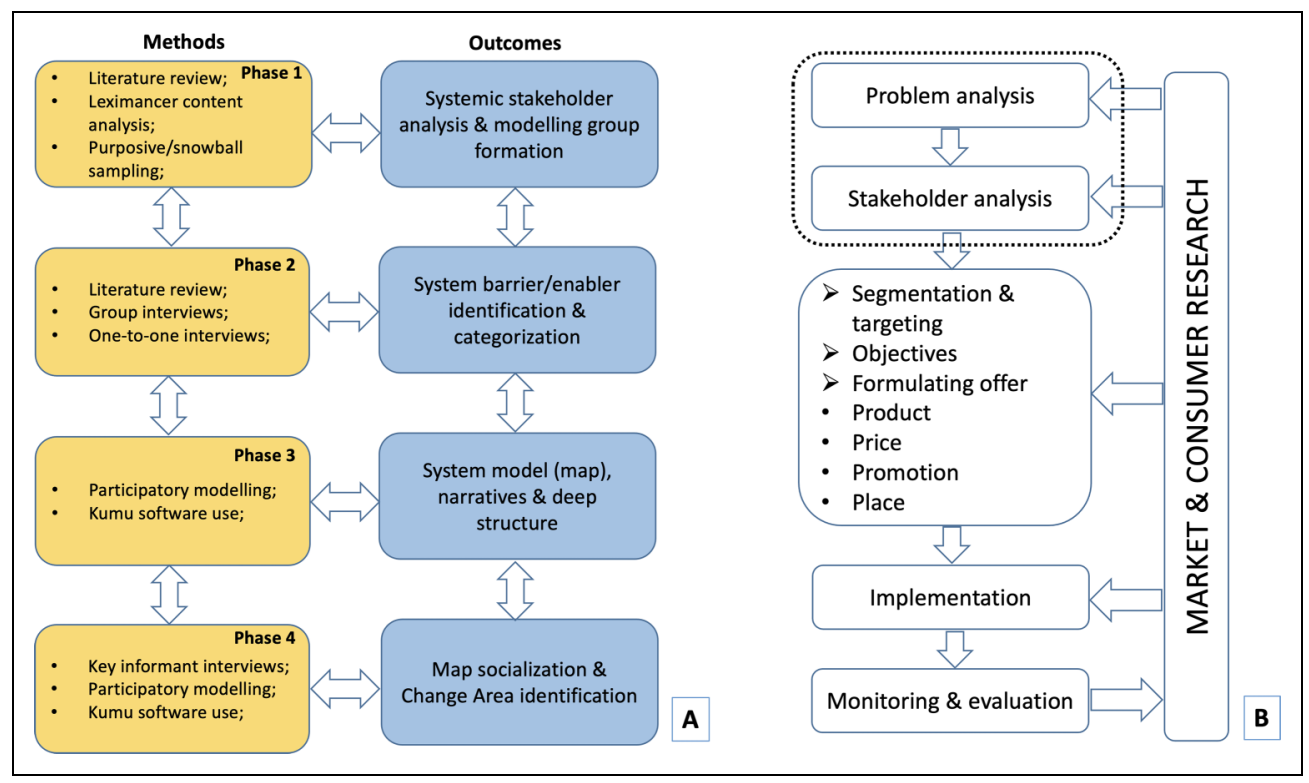

Figure 2. (A) multiphase research design. Two-way arrows signify iterative and reciprocal nature of the employed methodology and its outcomes. (B) A typical social marketing planning process. A dotted rectangle shows the areas primarily developed by participatory modelling, though segmentation and implementation can be also affected (adapted from Hastings 2007, p. 52).

Table 2. Research Samples, Data Collection Agents, Outcomes and Timeframes.

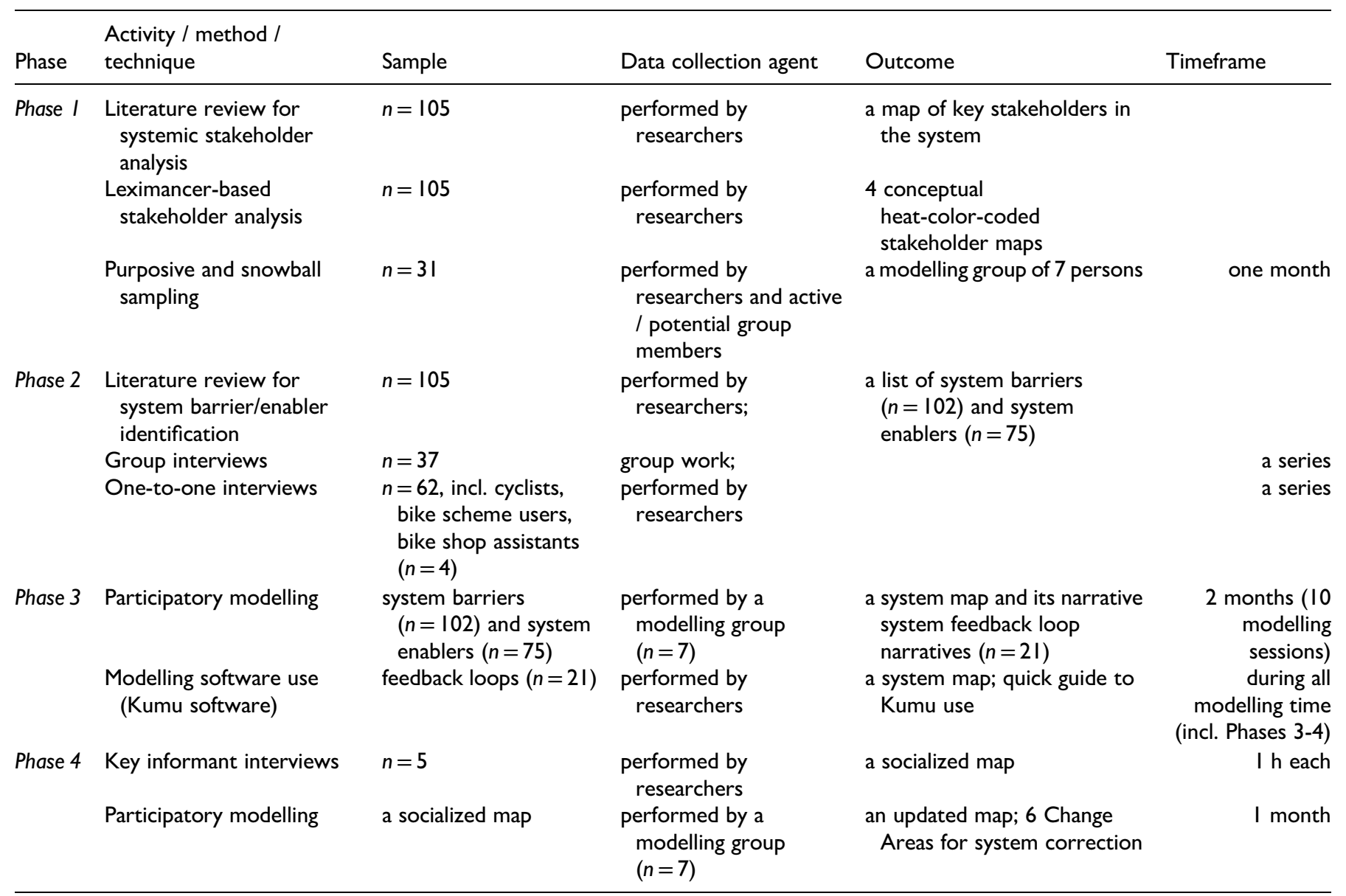


and non-academic publications; (c) citizen submissions (mostly on behalf of common system users); (d) media coverage; (e) websites of cycling- and transport-related organizations, clubs and associations; and (f) other sources. The resultant literature entries ( $n=105$ entries) were catalogued and analyzed for relevant stakeholders. Identified stakeholders were categorized as incumbents, challengers and regulating agencies, in accordance with Mechanism, Action, Structure theory (Layton 2015). Incumbents form a dominant group in the system and are interested in preserving the status quo, challengers are initiators of change to challenge the status quo, and regulating agencies are system operators responsible for its smooth running. A stakeholder can simultaneously be, for instance, a regulator and an incumbent (Figure 3).

The literature review was enhanced by content analysis via Leximancer software. According to Singleton, Straits, and Miller Straits (1993, p. 381) the basic idea behind content analysis is to "reduce the total content of a communication (e.g., all of the words...) to a set of categories that represent some characteristic of research interest." As a software tool for content analysis, Leximancer "automatically analyses your text documents to identify the high-level concepts in your text documents, delivering the key ideas and actionable insights you need with powerful interactive visualisations and data exports" (Leximancer n.d.). The entries $(n=105$; in Word and PDF formats) were uploaded into the program. These entries were selected in the previous literature review and were segmented as (a) academic publications $(n=21)$, (b) mass media and NGO publications $(n=71)$, (c) policy-related governmental reports $(n=13)$, and (d) combined $(a+b+c)$ sources (see Supplementary Word file S1). After uploading in the system, Leximancer output included conceptual heat-color-coded maps (see Supplementary Word file S1), representing the main concepts within the text and how they are related (themes) (Biroscak et al. 2017). Keywords helped to analyze the uploaded texts with respect to the identification of key stakeholders in the Galway cycling system (see Supplementary Word file S1). Figure 3 highlights key stakeholders in the problem system.

The formation of the modelling group relied on the content and systemic stakeholder analysis and was performed in such a way to represent all key stakeholders of the problem system. Initially a sampling frame $(n=31)$, listing all key stakeholders of the problem system, was generated from the literature review content analysis. Subjects from the developed sampling frame were contacted via telephone/e-mail. The contact message contained a proposition to participate in a series of 3-h participatory modelling sessions. The benefits, constraints and procedural questions were clearly explained to prospective session participants via face-to-face meetings. The sampling activities at this stage resulted in a group of prospective participants, some of whom decided to become active members of the modelling group. However, some prospective participants (both willing and unwilling to become active members of the modelling group) started to recommend other prospective participants, who might later become active members of the modelling group. Thus, the element of snowballing and networking was introduced to the process of the modelling group formation (Huff et al. 2017; Saunders, Lewis, and Thornhill 2019). Figure 4 shows how this process occurred. This was accompanied by the provision of in-depth information on stakeholders, their interests / goals and how these stakeholders are interactively incorporated into the system and how they relate to the system problems. It should be clear that active members of the modelling group could combine several roles, thus, for instance, being a member of a cycling NGO and representing the local civil engineering community.

The formation of the modelling group was considered to be completed when a fair representation of key stakeholders in the system was achieved (see Figure 3). Also, the modelling group should not be particularly large with optimal number of participants being within a range of 5-17 people (Hovmand 2014). As a result, these activities led to a modelling group of 7 active members, who represented:

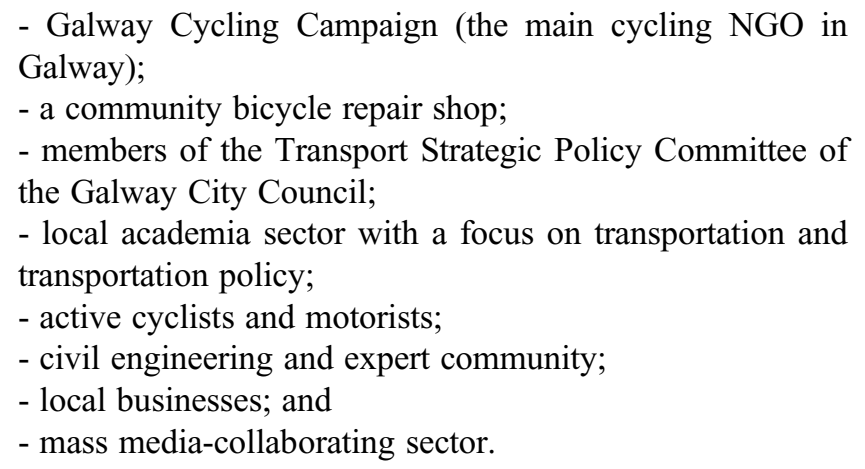

All members had large cycling experience in the city of Galway. Many of them also had extensive experience (over 20 years) in the consultation process within local transportation policy and decision-making, including the preparation of policy documents and transport infrastructure engineering plans. Representatives from some incumbent and regulating stakeholder groups (e.g., City Council Senior Engineer, local politicians) actively participated in system barrier/enabler list preparation in Phase 2, and as interviewees in the resultant map socialization in Phase 4.

It is pertinent to mention the active role of Galway Cycling Campaign in the work of the modelling group. The choice of NGOs to participate in the modelling sessions was straightforward due to their shared societal goals, as well as their capacity for macro-social marketing and for engaging in up-, mid-, and downstream efforts (Huff et al. 2017). NGOs typically have no power "to mandate changes in policy", and "must therefore engage in upstream marketing to do so" (Huff et al. 2017, p. 404). Likewise, members of Galway Cycling Campaign participate in the work of the Transport Strategic Policy Committee of the Galway City Council, and are thus fully aware of the logic of local decision-makers. A representative of Galway Cycling Campaign, who was the active member of the modelling group, is a member of such a committee. 


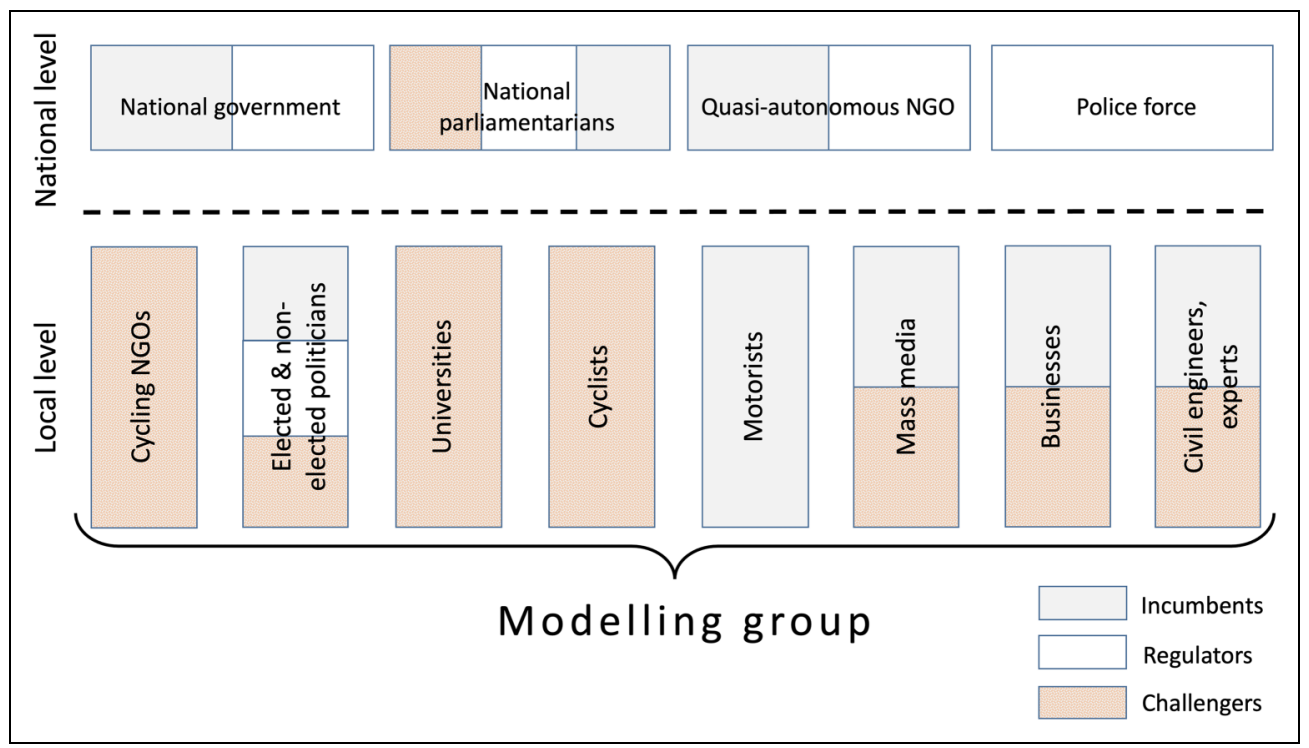

Figure 3. Key stakeholders in the problem system. The modelling group was formed to represent all key stakeholders of the system at the local level as the modelling group members held stakes in all these stakeholder groups.

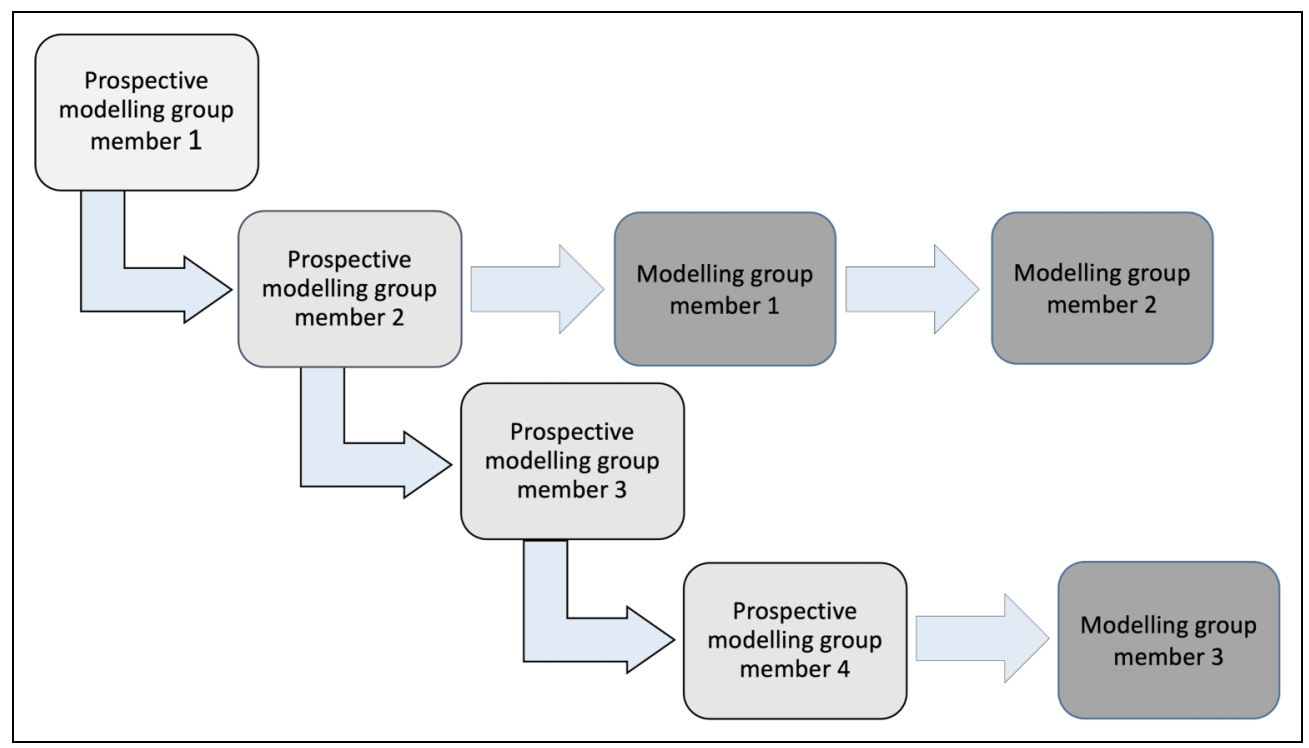

Figure 4. Snowballing/networking for the modelling group formation.

\section{Phase 2: System Barrier/Enabler Identification and Categorization}

The research used different sources to obtain data on the system-affecting barriers and enablers. These sources included: (a) a literature review (see Supplementary Word File S1 for the used literature) and (b) group and one-to-one interviews with system stakeholders (see Supplementary Word file S2). The potential omission of system-affecting factors at this stage was a possibility, and was compensated for in the course of the participatory modelling by a modelling group.
Group interviews involved discussions within several sessions of the National University of Ireland Galway Active Transport Group $(n=12)$. These sessions were hosted by transport/active mobility experts and community sector representatives. Similar discussions occurred within the sessions of Climathon in 2016, 2017 and $2018 \quad(n=25)$. Climathon (https://climathon.climate-kic.org) is a global one-day event that simultaneously gathers teams in many cities across the world to brainstorm solutions to multiple challenges facing our cities, including the issues of transport and active mobility. One of the researchers led the transport section of this event and 
was able to involve representatives from different stakeholder groups, including policy makers, NGOs, community sector and cycling experts, in discussions. The participants of these interviews were not the members of the modelling group.

For one-to-one interviews, this research used an intervieweradministered questionnaire (see Supplementary Word file S2) based on the two key elements - system barriers and system enablers. The objective here was to gather the opinions of the Galway cycling system users regarding the system's barriers and enablers, by naming which of these barriers and enablers were the most important in the system. The questionnaire was pre-tested with respect to (a) conformity to the Galway cycling system modelling aim, (a) readability, and (c) respondents' capacity to understand and answer questions. After pretesting the questionnaire among Boards.ie cycling-related groups, Climathon participants and cycling experts, certain changes to the questionnaire were made. For instance, the barrier/enabler clarification statements were added. The interviewees were actual Galway cycling system users $(n=62)$. The participants of these interviews were not the members of the modelling group. After 62 respondents were interviewed, it was considered that the interviews were unable to provide any new information on the Galway cycling system barriers and enablers and information saturation has been reached.

This phase generated 102 barriers and 75 enablers within the Galway cycling system. Mechanism, Action, Structure theory (Layton 2015), which analyzes the dynamics of complex social systems, was used for barrier and enabler categorization. It generated the following categories of system-affecting elements (both barriers and enablers): (a) structural elements, (b) social mechanism-related elements, and (c) those related to key system stakeholders and their interactions (Fligstein and McAdam 2012; Layton 2015).

\section{Phase 3: Generation of a Social Marketing-Based System Map}

This phase complied with methodological steps developed by Domegan et al. (2020) and Ricigliano (2012). It comprises the following actions:

- detailed analysis of system-affecting barriers / enablers and grouping them into barrier / enabler themes;

- origination of the stories, i.e., narratives of these barrier/ enabler themes via a series of individual feedback loops;

- connecting individual feedback loops into a qualitative system map, the cycling system map with a systems narrative (the map was printed out in a big format, which facilitated group discussions to identify system change areas and to formulate system-improving strategies); and

- identification of the dominant dynamics in the system that explains its behavior.

All loop narratives were consensually agreed between the members of the modelling group in the course of ten multi-hour system modelling sessions, which required the use of alterations and further agreements. Loop narratives, by organizing the rich system data in stories, acted as an element of qualitative data analysis. These rich qualitative narratives describe the behavioral dynamics.

\section{Phase 4: Map Socialization and Change Area Identification}

During Phase 4, the cycling system map and consensus-based narratives were socialized and confirmed by consultations with other system stakeholders via key informant interviews. This shifted participatory modelling based on a dedicated modelling expert group to systems stakeholder modelling. The system's change areas were identified via key informant interviews and the modelling group consultations. The Key Informant Interviews $(n=5)$ had a twofold aim:

1) to socialize the map in order to add new insights and/or eliminate possible mistakes and/or improve its modelling capacity; and

2) to act as a tool which links the system's mental models of other stakeholders with system's mental models of the modelling group members with the purpose of identifying system's resolutions and areas for change.

Key informant interviews represented a series of in-depth one-hour questioning and conversational events (audiorecorded where appropriate). The structure of the interviews was as follows:

1) a very brief introduction of the project;

2) questioning about specific loops (incl. elements and links) of the map;

3) questioning about which elements are missing or incorrect in the map; and

4) discussion of the system issues, illustrated with specific examples, and possible ways of the system correction.

The map allowed for the presentation, discussion and accumulation of rich materials on the system, including the interviewee personal multifaceted expertise and knowledge. The map helped structure ideas, present them to other system stakeholders in a cohesive and interdependent way, as well as organize solutions against the background of possible side-effects. The main elements of each interview were discussed with the modelling group members. The map was reiterated and corrected where necessary after consultations.

Further, the modelling group consultations, together with the key informant interviews among experts and other key stakeholders, focused on the generation of Change Areas to overcome the system's barriers and utilize the systems enablers. The map facilitated these efforts of system-wider stakeholders. A potential for impact and feasibility were the key criteria for determining Change Areas. When identifying Change Areas, special emphasis was usually given to the loops where the 
system's core behavioral dynamics is concentrated. Phase 4 generated six Change Areas, which are pivotal for the behavior modification, influence, alteration or correction. The description of the Change Areas is given below.

\section{Findings}

\section{The Cycling Social Marketing System Map}

The implementation of the participatory qualitative modelling to a localized cycling system resulted in a cycling system map. Figure 5 portrays the system's core behavior dynamics. This map, with 78 elements, organized in 21 causal feedback loops, acted as a consultation-based, socialized and visualized model of the current cycling system in Galway. A separate loop narrative or a story accompanies each loop. These individual loop narratives combined explain the overall behavioral dynamics (the system narrative). Below, we provide three examples of the loop narratives and the whole system narrative. These are the most important loops that comprise the system's core behavior dynamics. The system's core behavioral dynamics is determined by the interaction of the following three feedback loops:

a) output-based and autocratic decision-making (Loops 1-3, Figure 5),

b) an abundance of conflicted interests (Loop 5, Figure 5), and

c) the reinforcement of car-dominant paradigm in people's minds (Loop 9, Figure 5).

A few "bright spots" in the system include some rare patterns of cycling-friendly infrastructure, cycling positive image, societal healthy impacts and cycling convenience (see supplementary materials, i.e., Figure S1: Cycling System Map (PDF image) and Supplementary Word File S3 with the narratives of the cycling system map loops).

\section{Output-Based and Autocratic Decision-Making}

The narrative of Loop 1 (Figure 5) starts with system's element "Project-focused reasoning of decision-making" [Element 1], which implies the predominance of such type of reasoning among key decision-making echelons in the system. This element means an overwhelming focus on large projects, which are mostly budget driven. This focus was confirmed by Rau, Hynes, and Heisserer (2016, p. 52), who revealed the government's preoccupation with large-scale infrastructural transport projects, "often made without any meaningful public consultation." In this context, the main goal of city executives becomes spending money, i.e. the ability to spend allocated and available funds. Under this reasoning, real cycling system-improving measures and problem-fixing practices are overshadowed by "flagship" projects. This also means that measuring success (related to the cycling system improvement) in the form of outcomes becomes irrelevant, and it is substituted by measurements based on outputs [Element 2]. The reasoning behind prioritizing large projects and relying on outputs leads to neglecting consistent cycling system-improving work, which may look rather "small", but nevertheless healthy for the system [Element 3]. To further clarify the distinction between "outcomes" and "outputs", it was stressed that "outcomes" involve steady, consistent and incremental system-improving work based on proper consultation, while "outputs" mean one-off, sporadic and inconsistent realization of "big projects" that often disregard proper consultation. This output-based logic misses the main goal to sustainably improve the system.

All these cause actual anti-cycling outcomes, like deteriorating the visibility of cycling infrastructure, waste of allocated funds etc. [Element 4]. With budget prioritization ideas in mind driven by time constraints, proper consultations and expert advice become a redundancy or an obstacle in decisionmaking process. Consultations are neglected; they happen after the decisions are made or used as a tool to develop a strategy for rebuttal of public opinion. As such, the manifestation of the above attitude towards the consultation process and its actual outcomes demand city bureaucracy to employ "Autocratic mechanism of decision-making among city executive officers (bureaucracy)" [Element 5], which prevents adequate consultation. In this context, the lack of proper consultation and the autocratic mechanism of decision-making are inextricably connected. While various consultation activities are popular within the transportation and other public domains in Galway and Ireland, in general, the actual process of consultation is often undemocratic and may be even called a "slap in the face" by the Minister for the Diaspora and International Development (Advertiser, 25 July 2019, p. 18) or characterized by "absolutely no public input" (Advertiser, 18 January 2018, p. 32).

Thus, an autocratic decision-making mechanism helps to endorse these outcomes. This mechanism entails silo mentality and over-focus on specific areas of expertise, especially among civil engineers, thus cutting away helpful contributions and hearing other stakeholder voices that can positively affect the system. Another consequence of employing this mechanism is the lack of holistic thinking, which also blocks systemic understanding of the issues and proper decision-making [Elements 6-7]. Such narrowing-down of focus and reductionism of thought strengthen the need in maintaining project-based reasoning, thus effectively closing this vicious loop.

\section{An Abundance of Conflicted Interests}

This important loop acts as a "bridge" between (a) decisionmaking mechanisms (characterized by autocratism at local level and passiveness in cycling development at the national level), tightly coupled with cycling marginalization [Loop 4], on the one hand, and (b) several loops related to car-centered paradigm, design, thinking, planning and management (in traffic, urban and other domains) [Loop 9], on the other hand. The modelling group pinpointed several categories of multiple conflicts of interests, operable in the system, including those related to incentivization of car-centered design, promotion of car-centered community or relying on car-centered activity 


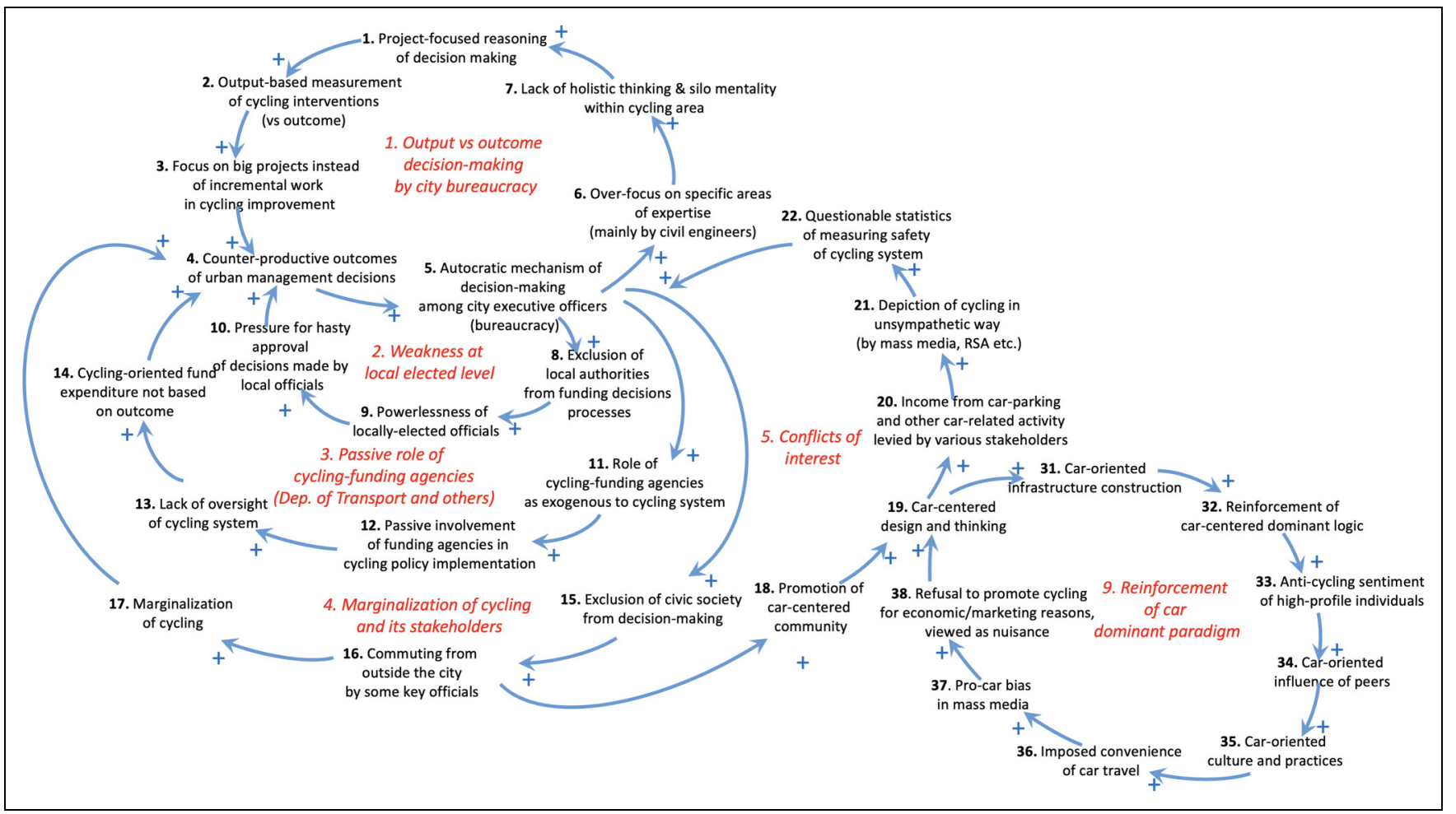

Figure 5. Core dynamics of the cycling system (for the full map, see figure SI: cycling system Map). Arrows show the direction of influence. A "+" polarity sign indicates that increasing the cause variable will increase the effect variable, with everything else kept at a constant level. All loops here are reinforcing, i.e. amplifying change, in contrast to balancing loops, i.e. self-correcting change. All elements and loops have titles consensually agreed by the modelling group members themselves.

incomes by different stakeholder groups, including local authorities, retailers, and schools. For the sake of decreasing the complexity of the map and keeping it manageable, it was agreed to amalgamate all these conflicts in one loop.

The drivers, which trigger the dynamics of this loop, are crucially important. Especially, it involves "Car-centered design and thinking" (Element 19], which is pivotal for the whole cycling system, thus signaling this element's participation in core dynamics of the system. The elements within Loop 9 simultaneously generate and rely on incomes from car-centered activities, such as car-parking, levied by various stakeholders [Element 20]. These stakeholders also need to often portray cycling in unsympathetic or biased light and resort to questionable statistics of measuring safety of the cycling system [Elements 21 and 22]. Element 22 means that biased stakeholders may be interested in the curtailment of the cycling system, while they are also interested in keeping their views and practices intact. To this extent, such attitudes and policy require substantiation of the autocratic decision-making mechanism [Element 5], which closes this loop. In this loop, "the [current] goals of the system", marked by an abundance of vested interests of multiple stakeholders, are evident (Wooliscroft 2021, p. 120).

\section{The Reinforcement of car-Dominant Paradigm in People's Minds}

This is a multi-elemental and powerful loop, which is initiated by "Car-centered design and thinking" [Element 19]. Such design and planning is effective in originating the car-oriented infrastructure. The construction of such infrastructure develops, maintains and reinforces car-centered dominant logic [Element 32]. Within this logic, "Anti-cycling sentiment of high-profile individuals" and "Car-oriented influence of peers" are explainable, thus strengthening "Car-oriented culture and practices" and "Imposed convenience of car travel" [Elements 33-36]. "Pro-car bias of mass media" [Element 37] follows the dominant logic. All these lay the foundation of refusing to promote cycling, (viewed by many as a nuisance), for economic and marketing reasons [Element 38], thus giving a feedback to "Car-centered design and thinking". In general, this loop acts as a vivid manifestation and explanation of mental framing, which shapes how stakeholders view reality and determines many outcomes at various levels of a system (Domegan et al. 2019). This loop signifies about "the mindset or paradigm out of which the system...arises", which is based on car-centric thinking and culture (Wooliscroft 2021, p. 120). 


\section{The Whole Behavioral System Narrative}

The core behavioral dynamics features two "centers of gravity" of the Galway cycling system:

1) Output-based and autocratic decision-making (based on output vs. outcome system management, decisionmaking autocracy, deficient consultation process [Loop 1]; weak local power [Loop 2]; passiveness of cycling policy implementation [Loop 3], which result in the counter-productive outcomes in the cycling infrastructure [Element 4] and cycling marginalization [Loop 4), and

2) Reinforcement of car-dominant paradigm in people's minds, which negatively affects cycling image, strengthens car-dependent paradigm among nearly all stakeholders, and impinges upon cycling safety [Loop 9].

These are responsible for the bulk of the behavioral dynamics in the system. The "Conflicts of interest" loop [Loop 5] acts as a bridge between the two "centers of gravity", highlighting the importance of conflict, at all levels, in the current operation of the Galway cycling system. Conflicting interests here manifest as "inherent tensions between the pursuit of self-interests and larger societal interests" of various stakeholder groups (Lewin, Strutton, and Paswan 2011, p. 340).

The modelling of the existing system enablers (see supplementary materials, Figure S1: Cycling System Map, as a PDF image, and Supplementary Word file S3) confirms their insufficient and irregular level of occurrence for the overall system improvement, though they act as important tools that keep the system alive and operable.

\section{Map Socialization Results}

In summary, all map socialization participants endorsed the system map and agreed with its key dynamics. They confirmed that the current cycling system in Galway is driven by the two "centers of gravity": output-based and proper consultationlacking decision-making and car-centered thinking, while these two centers are linked and reinforced by conflicting interests. All other loops and issues (cycling safety, lack of provisioning for bad weather, lack of cycling infrastructure etc.) either ensue from these three and/or strengthen them.

The issue of duality between autocratic and democratic mechanisms of decision-making was thoroughly discussed in the course of the map socialization interviews, which confirmed the centrality of this theme in the system map. The interview participants agreed with the decision-making dynamics, shown primarily in Loops 1 and 2 of the system map, confirming the correctness of relationships between the elements in these loops. However, apart from the failures of the autocratic mechanism of decision-making, there are also issues associated with a democratic mechanism of decision-making. One interview participant described these issues in the following way:
"For me, the problem is also with the democratic mechanism.... I prefer more power to reside with non-elected officials rather than elected politicians who are major causes of planning disasters that we have."

The modelling group members shared similar concerns. They argued that the decisions of locally elected politicians in relation to cycling could be detrimental. In addition, an interview participant stressed that locally elected politicians are often unable or unwilling to implement (unpopular) fiscal measures (for instance, raising the property tax) like it is done in many cities of the world. As such, there are "significant issues" with cycling financing at the local level, as when funds arrive from the national level it is difficult to question their allocation. The socialization confirmed the loop on the marginalization of cycling. For instance, people often say and mean "cyclists as separate group, but hardly segregate car drivers as a group."

An interview participant mentioned the excessive power centralization in Ireland, as one of the contextual influences upon the Galway cycling system. Rau, Hynes, and Heisserer (2016, p. 46), relying on the work by Jacobson and Kirby (2006), call such over-centralization "a highly centralised tradition of governance and decision-making", specially marking "weak and under-resourced local authorities and a long tradition of clientelism." Likewise, Reidy (2018) provided multiple evidence confirming this over-centralization, for example, revealing that, among the EU countries, Ireland is the second last with respect to raising taxes at the local level. The map socialization activities confirmed the system's behavioral dynamics and provided interesting and important details about single feedback loops and separate relationships within the system.

\section{Change Areas}

Change Area I: Construction of Bike-Parking Facilities. This Change Area implies the construction of publicly visible and modern bike-parking facilities at the strategic sites offering the most positive impact on the Galway cycling system. The site locations and other construction details originate after the consultations with the Galway cycling system experts, which is crucial for their planning. A modelling group member argued:

\begin{abstract}
"I would treat bike parking as the most fundamental form of infrastructure for cycling. I would go so far as to state that if a local authority is building cycle paths but not providing cycle parking then this proves that the intent is not to promote cycling but something else. We absolutely need comprehensive cycle parking at all destinations in the city."
\end{abstract}

Dealing directly with structural barriers may address all vital elements of the core dynamics, including the system mismanagement, dubious consultation process, autocratic mechanisms of decision-making, vested interests, and car-centric thinking. The construction of such parking facilities might take into 
consideration intra-modal mobility, i.e. linking cycling to other means of transportation, such as public buses and trains at bus hubs and train stations.

Change Area 2: Bike Maintenance Organization. This Change Area means organization of support to the system bike shops and bike-maintenance centers, especially on-road bike maintenance facilities. This support may have financial (tax, etc.), logistical (facilities, equipment etc.), managerial (personnel, advice etc.), commercial (clientele, orders etc.), legislative and other dimensions. In analogy with Change Area 1, it is structural in character, but affects elements of the core dynamics, since it caters for the main medium and unit of the Galway cycling system - the bicycle and a cyclist, respectively. The way the system provides and maintains the bicycle asset and its relevant equipment, as well as caters for its main user, is quintessential for the whole system. When analyzing Change Area 2, a modelling group member stressed:

"If we want to increase maintenance then the obvious pathway for
this is to have police inspecting bicycles for mechanical defects.
This would then drive a market for maintenance activities... I
suspect at the moment... many senior police see cycling as an
obstacle to their real job - which they interpret as facilitating
motoring. So, the real leverage point is police attitudes.

Change Area 3: Best Practice Research and Replication. This Change Area addresses the research into good cases of the cycling infrastructure in Galway. Galway city features some extremely rare examples of cycling-friendly infrastructure. The analysis of such cases could be context-driven, personalitybased and innovation-triggered. The major emphasis should be given to international examples of cycling-related best practice, especially in the Netherlands and Denmark. Relating to the infrastructure, this Change Area can improve the system and demonstrate more interest towards high quality outcomes, rather than, often questionable, big projects based on outputs.

Change Area 4: Cycling Champions and Cycling Officer Position. This Change Area stipulates the establishment of Cycling Champions at all power levels, including a Cycling Officer Position in the City Council. The necessity to introduce and implement this Change Area in the Galway cycling system is dictated by the need to raise the attention to cycling within the upper echelons of power. The situation needs to be addressed by establishing a specialized position of a Cycling Officer in the City Council. This person, who should be an expert in cycling mobility organization, must have sufficient power to promote cycling as a viable and effective alternative to auto mobility. However, the realization of this Change Area could be dependent on other factors. For instance, a modelling group member argued:

"If you have a power hierarchy focused on car culture and promoting cars, then giving them money for cycling champion can be a way for them to hire another roads engineer and keep doing business as usual...If the councils were being assessed on cycling outcomes, then they would have an interest in hiring cycling champions for the purpose of promoting cycling."

Change Area 5: Change of Consultation Process and its Role. This Change Area implies the application of a participatory approach to consultations with city's cycling experts under which they become real participants in decision-making process. The discriminatory character of consultations between city officials and cycling experts, when knowledge and expertise of these experts are mostly neglected, is one of top barriers that drives very powerful negative dynamics in the Galway cycling system. Such discriminatory type of consultations became the formidable foundation for car-centric design and thinking, with which it exists in autocatalytic feedback relationships. The change in the process and outcomes of a dialogue between city officials and the cycling community in Galway is an effective and urgent solution in the direction of the system improvement.

Change Area 6: Collaboration with Media. This Change Area means collaboration with traditional mass media and social media for improving cycling image and mitigating car-centered bias in the Galway cycling system. The pivotal role of media in affecting the Galway cycling system was confirmed in Loop 9, which describes how the car dominant paradigm in Galway is reinforced, including mass media. This role is also evident in Loop 5 by exacerbating the conflicts of interests. The same was stressed during the map socialization. To this extent, a Change Area targeted at altering the role of media in framing the specific image of cycling in Galway is of huge importance. The specific work within this Change Area involves the vertically integrated multi-stakeholder one-task teams, including City Council representatives (e.g., urban planners), media, civil engineers, Galway Cycling Campaign members, local businesses, and system users. Such teams can act as a tool of using media capacity to serve the Galway cycling system.

Specific interventions to address the problem system were not planned for this research. However, certain outcomes of the activities within the highlighted change areas became evident after the modelling sessions were completed, especially due to the work of Galway Cycling Campaign. This organization started active promotion of the establishment of the Cycling Officer position both in Galway City and County Councils (Galway Advertiser, 10 September 2020), so the government took a decision to provide funding for Galway City Council walking and cycling jobs (Galway Advertiser, 11 February 2021). This makes a decisive behavior change within Change Area 4. Realization of Change Area 3 (Best practice research and replication) saw a series of successful webinars and events, like the one with the participation of the Dutch Ambassador to Ireland and the Dutch Cycling Embassy network to adapt Dutch experience for local circumstances (Galway Advertiser, 24 September 2020). 
The Covid-19 pandemic facilitated the allocation of funds for the development of cycling infrastructure, which meant a breakthrough for Change Area 1 (Galway Advertiser, 11 February 2021). The collaboration of Galway Cycling Campaign and City Council within the City Mobility Team (Galway Advertiser, 9 July 2020) may signify an important change in the consultation process (Change Area 5), but the anticipation of the quick progress in this important element of the system is hardly possible due to a significant rate of the system inertia. However, outstanding progress has been achieved in Change Area 6 (Collaboration with media), which is marked by an increase in publications on the cyclingrelated topics in the local newspapers. Local politicians initiated a campaign "to provide public bike repair and pump stations across the cycling network in the city", which may improve Change Area 2 (Galway Advertiser, 5 November 2020, p. 30).

\section{Discussion}

The purpose of this study is to show how the implementation of participatory qualitative modelling to explore networks of feedback loops can empower social marketing and macromarketing in capturing more complexity for wide-scale behavior change and in understanding the interaction between marketing systems and society. This empowers social marketers, macromarketers and other stakeholders with a methodological approach applicable in planning and executing multi-level systemic behavior change interventions that capture, in a better way, a system's complexity. This methodological approach puts bigger emphasis on what is missing or insufficiently developed in social marketing and macromarketing - the analysis of circular causality of complex social systems and participation of system-wide stakeholders in understanding system complexity (Carvalho and Mazzon 2020; Wooliscroft 2021).

Since grasping behavior complexity should precede strategic responses to improve the problem, understanding complex causal dynamics has direct implications for social marketing interventions, including their focus, impact and outlines. The suggested participatory modelling acts as a further methodological substantiation of systemic approaches in social marketing. This research accentuates the vitality of such systems thinking tools as multi-stage systemic stakeholder analysis and stakeholder participation (McHugh, Domegan, and Duane 2018) and causal loop diagrams as highly socialized, consensual and modifiable boundary objects (Hovmand 2014).

These tools are vital for macromarketing too, since they help shed light on some issues, themes and challenges that macromarketing is preoccupied with and deems important/interesting, like government regulation and policies, normative ethics, strategic action fields, conflicts, quality of life, market efficiency and injustice, institution building and failures in development (Layton 2015; Layton and Grossbart 2006; Hunt, Hass, and Manis 2021). In the context of this research, the implementation of system thinking tools might also assist in combating marketing thought fragmentation by bridging several major fields of marketing study, i.e. modeling, strategy, and macromarketing
(Hunt, Hass, and Manis 2021). Such implementation also substantiates the extraordinary broadness and interlinking character of the contemporary macromarketing field.

Therefore, five systems thinking-based tools that are specifically applicable in social marketing interventions and macromarketing studies are as follows:

a) qualitative modelling of complex causal dynamics and participatory techniques for developing mental models as modifiable boundary objects (a general approach);

b) problem system boundary identification and systemic stakeholder analysis;

c) problem system barrier/enabler identification, categorization and organization in feedback loops;

d) narration and analysis of system's individual positive and negative feedback loops, as well as explicating the whole system feedback structure via a narrative (story); and

e) strategic insights from the resulting model as change areas for a behavior dynamics correction.

Members of the Galway cycling system's modelling group confirmed the importance of personalities in affecting the system dynamics. They provided examples when a single personality was responsible for changes in the Galway cycling system or analogous systems in Ireland. The most striking example in Ireland is the activity of Simon Wall, an architect with Mayo County Council. His decisive role in the Westport town urban planning and active mobility development, as well as in the use of consultation and participatory approaches, was exemplary and led to the town regeneration (O'Donoghue 2017). Moreover, such personalities can be at each level of the system and within all stakeholder groups, including incumbents, challengers and regulators.

The manifestation of systems stakeholder participatory qualitative modelling may have important implications for social marketing interventions. The cycling system map shows that a conventional social marketing intervention within this system will have a limited impact, may easily cause negative side-effects and can be reversible, if not sustained or supported with systemic approaches. Powerful and all-penetrating carcentric mentality (such mentality is in autocatalytic feedback relationship with car-centric design and infrastructure), demonstrated by different stakeholders in the Galway cycling system and strengthened by vested, often conflicted, interests, as well as by output-based autocratic decision-making and policy planning, is resistant to a traditional social marketing micro intervention aimed at one specific audience within the system. To this extent, various cycling short-term events, educational campaigns or greenway construction, when implemented without addressing other elements, structures, roles, processes, relations, contexts and functions of the system, are limited in their ability to improve the system and incapable of transforming its dominant car-centered paradigm.

As a result, non-holistic interventions, which are often presented as a silver bullet, might lead to negative consequences 
due to the feedback links. For instance, the national campaigns of greenways, despite their undisputable benefits, will unlikely produce the desired effect on the Galway cycling system and commuting transportation. Moreover, such greenways may segregate cycling mobility as something linked only to tourism/recreation and reliant on car transportation to the greenway places. Likewise, financial investment in cycling without the shift from car centrism and impaired consultation practices may fail to make behaviors more sustainable. On the contrary, the effect of the financial investment may be even negative.

System modelling allows capturing complex interrelationships of the elements within the system. For instance, the system element of "Autocratic mechanism of decision-making among city executive officers (bureaucracy)" may produce quite positive results for the system, if it rests on the adherence to modern understanding of the sustainability in transport, negation of car centrism (as a principle) and effective management practices. Likewise, a democratic procedure, associated with many locally elected politicians, may produce negative results if these politicians rule by veto. Therefore, the actual leverage in the system is behaviorally dynamic by its nature. Change is in a state of constant flux and is dependent on multiple elements, which is a true manifestation of complexity (Jackson 2019). This stipulates the need in systemic interventions affecting multiple areas of behavior simultaneously.

Some elements of the system (e.g., outcome-based nonautocratic logic of decision-making, elimination of vested interests and the required shift in the car-centric paradigm) represent necessary conditions for improving the cycling system. These are "core elements [which] indicate a strong causal relationship with the outcome" (Pappas and Woodside 2021, p. 3). Without their presence, many elements (e.g., dedicated cycling-focused officials) are insufficient to correct the situation. The latter elements are peripheral and indicate weaker relationships (Pappas and Woodside 2021).

Social marketing's understanding of complex causal dynamics and addressing complex issues is impossible without taking on board a broad stakeholder perspective, which includes different insights, knowledge and experience of multiple stakeholders (McHugh, Domegan, and Duane 2018). Social marketing regularly practices community involvement (e.g., community-based social marketing; McKenzie-Mohr 2011). However, on a big scale, social marketing fails to use the combination of participatory methodology and understanding complex causal dynamics (Anibaldi, Carins, and Rundle-Thiele 2020).

From the methodological perspective, the implementation of participatory modelling in this research showed a number of valuable results, which can be further developed. One includes the system map as a visual tool with a lot of potential for demonstration. This potential should be used to the full. User-friendly optimization of available modelling software packages is one of prospective directions.

Data-driven verification of originated models via various quantitative methods (Sterman 2018), such as structural equation modelling, is an important trajectory, recommended for further systems thinking-based social marketing research. It is recommended that consideration is given to the potential of fuzzy-set qualitative comparative analysis (QCA), which can merge both qualitative and quantitative approaches. The latter differs QCA from other variance-based techniques, like structural equation modelling (Pappas and Woodside 2021). This would not circumvent general complexity of social systems, but can render a better approximation of their intricacy.

\section{Conclusion}

The paper contributes to understanding the potential of participatory qualitative modelling with system stakeholders and feedback loops for multi-level behavior change. This shifts participatory modelling based on a dedicated modelling group to system-wide stakeholder modelling. When loops are generated as part of participatory qualitative modelling processes, social marketing interventions could offer a number of benefits. These benefits primarily include: (a) the incorporation of the knowledge of complex causal dynamics of systems in social marketing interventions, which need to be reformatted into systemwide social change programs; (b) systemic stakeholder analysis and engagement; and (b) participatory system modelling methodologies. Social marketing hitherto has been good at understanding the parts of a problem and implementing change in relation to the problem parts. It is time for social marketing to fully develop its macro capabilities to understand the whole and parts of a problem to implement transformative change.

Both the research design and the complex objective nature of the analyzed context (general complexity) impose certain limitations. First, there is a possibility of introducing a certain bias in the system modelling due to reliance on some stakeholders to exclusion of others. Heterogeneous interests of system stakeholders may undermine stakeholder participation efforts. Thus, great care should be given to engaging appropriate system stakeholders in a modelling process.

Second, any modelling group members require significant time investments to understand multivariate causality of wicked issues. Participatory activities need lots of practice, patience and psychological empathy with a simultaneous consideration of procedural rigor and strict adherence to the protocols. Therefore, to combat this challenging character of group-based modelling activities, such tools as Delphi techniques can help generate qualitative data in a more efficient way (Rees et al. 2017).

Third, any maps, which try to render behavioral complexity, are significantly over-simplified as compared to the actual complexity of the systems. Simplification is a limitation, on the one hand, and a tool, on the other hand. The latter means that in order to have an operable model of a system, simplification is indispensable. Specifically for this research, it primarily means the exclusion of several adjacent systems (e.g., other active mobility systems) from the analysis of their impact on the problem system. Such logic is confirmed by Sterman (2000, p. 89), who stresses that "but for a model to be useful, it must...simplify rather than attempt to mirror an entire system in detail." 
Fourth, better knowledge of the system and its specific high impact zones do not automatically lead to the manifestation of this knowledge. Besides, a system-wide intervention, which is based on system modelling, may look too cumbersome for various system actors, who often rely on simplistic approaches. Moreover, even proper decisions, empowered by correct system modelling, may fail because of poor implementation.

However, these limitations, no matter how strong they are, are not an excuse to avoid using the potential of systems thinking tools for social marketing. Moreover, overcoming these limitations can become an important element, which facilitates utilization of participatory qualitative modelling for social marketing purposes. We argue that collaborative qualitative forms of modelling can be particularly advantageous at the early stages of system conceptualization, when system-wide stakeholders, often without modelling skills, can learn the process of systemic complexity comprehension. As such, knowledge of system feedback loops, obtained as a system-wide stakeholder participation endeavor, can be firmly entrenched into the armamentarium of social marketing techniques.

\section{Associate Editor}

Ann-Marie Kennedy.

\section{Acknowledgments}

The authors fully acknowledge the following members of the Galway cycling system modelling group: Shane Foran, Dr. Fiona Concannon, Daniel Clabby, Daniel Gosling, Paul O’Donnell, Prof. Michael Hynes, and Dr. Kevin Jennings.

\section{Declaration of Conflicting Interests}

The author(s) declared no potential conflicts of interest with respect to the research, authorship, and/or publication of this article.

\section{Funding}

The author(s) disclosed receipt of the following financial support for the research, authorship, and/or publication of this article: This work was supported by the National University of Ireland Galway (Hardiman PhD Scholarships).

\section{ORCID iDs}

Dmitry Brychkov (iD https://orcid.org/0000-0003-0341-9061

Christine Domegan (D) https://orcid.org/0000-0001-7975-9041

\section{Supplementary Materials}

The following are available: Figure S1: Cycling System Map (PDF image); Supplementary Word file S1 (Leximancer content analysis); Supplementary Word file S2 (Results of group and one-to-one interviews); Supplementary Word File S3 (Narratives of cycling system map loops).

\section{References}

Anibaldi, Renata, Julia Carins, and Sharyn Rundle-Thiele (2020), "Eating Behaviors in Australian Military Personnel: Constructing a System of Interest for a Social Marketing Intervention," Social Marketing Quarterly, 26 (3), 229-43.

Biroscak, Brian J., Carol A. Bryant, Mahmooda Khaliq, Tali Schneider, Anthony D. Panzera, Anita Courtney, et al. (2019), "Using System Dynamics Modeling to Evaluate a Community-Based Social Marketing Framework: A Computer Simulation Study," Journal of Social Marketing, 9 (1), 53-76.

Biroscak, Brian J., Jenny E. Scott, James H Lindenberger, and Carol A. Bryant (2017), "Leximancer Software as a Research Tool for Social Marketers: Application to a Content Analysis," Social Marketing Quarterly, 23 (3), 223-31.

Black, Laura J. and David F. Andersen (2012), "Using Visual Representations as Boundary Objects to Resolve Conflict in Collaborative Model-Building Applications," Systems Research and Behavioral Science, 29 (2), 194-208.

Brennan, Linda, Josephine Previte, and Marie-Louise Fry (2016), "Social Marketing's Consumer Myopia: Applying a Behavioural Ecological Model to Address Wicked Problems," Journal of Social Marketing, 6 (3), 219-39.

Bryant, Carol A., Anita H. Courtney, Robert J. McDermott, James H. Lindenberger, Mark A. Swanson, Alyssa B. Mayer, et al. (2014), "Community-based Prevention Marketing for Policy Development: A new Planning Framework for Coalitions," Social Marketing Quarterly, 20 (4), 219-46.

Byrne, David and Gill Callaghan (2014), Complexity Theory and the Social Sciences: The State of the Art. Abingdon, Oxon, UK: Routledge.

Carroll, James, William Brazil, Bruno Morando, and Eleanor Denny (2020), "What Drives the Gender-Cycling-gap? Census Analysis from Ireland," Transport Policy, 97 (2020), 95-102.

Carvalho, Hamilton Coimbra and José Afonso Mazzon (2020), "Embracing Complex Social Problems," Journal of Social Marketing, 10 (1), 54-80.

Conejo, Francisco and Ben Wooliscroft (2015), "Brands Defined as Semiotic Marketing Systems," Journal of Macromarketing, 35 (3), 287-301.

Corner, Adam and Alex Randall (2011), "Selling Climate Change? The Limitations of Social Marketing as a Strategy for Climate Change Public Engagement," Global Environmental Change, 21 (3), 1005-14.

Coyle, Jeoff (2009), "Qualitative and Quantitative Modelling in System Dynamics," in System Dynamics. Encyclopedia of Life Support Systems, Volume 2, Yaman Barlas, ed. Oxford, UK: Encyclopedia of Life Support Systems (EOLSS) Publishers Co. Ltd./UNESCO, 33-49.

Diamond, Jared (1987), "Soft Sciences are Often Harder Than Hard Sciences," Discover, 8 (August), 34-9.

Dibb, Sally (2014), "Up, Up and Away: Social Marketing Breaks Free," Journal of Marketing Management, 30 (11-12), 1159-85.

Domegan, Christine, Dmitry Brychkov, Patricia McHugh, Áine McNamara, Katharine Harkin,, Christine Fitzgerald, et al. (2020), "Marketing Systems: A Listen, Learn, Leverage Framework," Journal of Macromarketing, 40 (3), 380-95.

Domegan, Christine, Patricia McHugh, Michelle Devaney, Sinead Duane, Michael Hogan,, Benjamin J. Broome, et al. (2016), "Systems-thinking Social Marketing: Conceptual 
Extensions and Empirical Investigations," Journal of Marketing Management, 32 (11-12), 1123-44.

Domegan, Christine, Patricia McHugh, Tina Flaherty, and Sinead Duane (2019), “A Dynamic Stakeholders' Framework in a Marketing Systems Setting," Journal of Macromarketing, 39 (2), 136-50.

Fligstein, Neil and Doug McAdam (2012), A Theory of Fields. Oxford, UK: Oxford University Press.

Freeman, R. Edward (1984), Strategic Management: A Stakeholder Approach. Boston, MA: Pitman Publishing.

French, Jeff and Ross Gordon (2019), Strategic Social Marketing: For Behaviour and Social Change, 2nd, London, UK: Sage Publications.

Hastings, Gerard (2007), Social Marketing - Why Should the Devil Have All the Best Tunes? Oxford, UK: Butterworth-Heinemann.

Hastings, Gerard and Christine Domegan (2018), Social Marketing: Rebels with a Cause, 3rd. Abingdon, Oxon, UK: Routledge, 291309.

Hovmand, Peter S (2014), Community Based System Dynamics. New York, NY: Springer Science + Business Media.

Huff, Aimee Dinnin, Michelle Barnhart, Brandon McAlexander, and Jim McAlexander (2017), "Addressing the Wicked Problem of American Gun Violence: Consumer Interest Groups as Macro-Social Marketers," Journal of Macromarketing, 37 (4), 393-408.

Hunt, Shelby D., Ashley Hass, and Kerry T. Manis (2021), “The Five Stages of the Macromarketing Field of Study: From Raison D'etre to Field of Significant Promise," Journal of Macromarketing, 41 (1), 10-24.

Hynes, Mike (2017), “At a Crossroads: Investigating Automobility and its Implications for Local Urban Transport Policy Design," Urban Science, 1 (2), 1-16.

Hynes, Mike and Eibhlín Seoighthe (2018), "Heading in the Right Direction? Investigating Walkability in Galway City, Ireland," Urban Science, 2 (2), 1-20.

Jackson, Michael C (2019), Critical Systems Thinking and the Management of Complexity. Hoboken, NJ: John Wiley \& Sons, Inc.

Jacobson, David and Peadar Kirby (2006), "Globalisation and Ireland," in Taming the Tiger: Social Exclusion in a Globalised Ireland, Davis Jacobson, Peadar Kirby P, and Deiric Ó Broin, eds. Dublin, Ireland: TASC/New Island Books, 23-44.

Kadirov, Djavlonbek (2018), "Towards a Theory of Marketing Systems as the Public Good," Journal of Macromarketing, 38 (3), 278-97.

Kapitan, Sommer (2020), "Macro-social Marketing as a Tool to Increase the Share of Renewable Energy in Developing Island Nations," in Macro-Social Marketing Insights: Systems Thinking for Wicked Problems, Ann-Marie Kennedy, ed. New York, NY: Routledge, 27-53.

Kennedy, Ann-Marie (2017), "Macro-social Marketing Research: Philosophy, Methodology and Methods," Journal of Macromarketing, 37 (4), 347-55.

Kennedy, Ann-Marie (2020), Macro-Social Marketing Insights: Systems Thinking for Wicked Problems. New York, NY: Routledge.

Kubacki, Krzysztof, Dariusz Siemieniako, and Linda Brennan (2020), "Building Positive Resilience Through Vulnerability Analysis," Journal of Social Marketing, 10 (4), 471-88.
Kunc, Martin (2017), "System Dynamics: A Soft and Hard Approach to Modelling," in Proceedings of the 2017 Winter Simulation Conference, Las Vegas, NV, USA, 3-6 December 2017, Wai Kin Victor Chan, Andrea D'Ambrogio, Gregory Zacharewicz, Navonil Mustafee, Gabriel Wainer, and Ernie Page, eds. Piscataway, NJ: IEEE Press, 597-606.

Lane, David C (2000), "Diagramming Conventions in System Dynamics," Journal of the Operational Research Society, 51 (2), 241-45.

Lawson, Anneka Ruth, Karen McMorrow, and Bidisha Ghosh (2013), "Analysis of the Non-Motorized Commuter Journeys in Major Irish Cities," Transport Policy, 27 (2013), 179-88.

Layton, Roger A (2015), "Formation, Growth, and Adaptive Change in Marketing Systems," Journal of Macromarketing, 35 (3), 302-19.

Layton, Roger A. and Christine Domegan (2021), "The Next Normal for Marketing - The Dynamics of a Pandemic, Provisioning Systems, and the Changing Patterns of Daily Life," Australasian Marketing Journal, 29 (1), 4-14.

Layton, Roger A. and Sarah M. Duffy (2018), "Path Dependency in Marketing Systems - Where History Matters and the Future Casts a Shadow," Journal of Macromarketing, 38 (4), 400-14.

Layton, Roger A. and Sanford Grossbart (2006), "Macromarketing: Past, Present, and Possible Future," Journal of Macromarketing, 26 (2), 193-213.

Lewin, Jeffrey E., David Strutton, and Audhesh K. Paswan (2011), "Conflicting Stakeholder Interests and Natural Gas: A Macromarketing Perspective," Journal of Macromarketing, 31 (4), 340-58.

Leximancer (n.d.) (accessed on February 8, 2021), [available at https:// info.leximancer.com/].

McHugh, Patricia, Christine Domegan, and Sinead Duane (2018), "Protocols for Stakeholder Participation in Social Marketing Systems," Social Marketing Quarterly, 24 (3), 164-93.

McKenzie-Mohr, Doug (2011), Fostering Sustainable Behavior: An Introduction to Community-Based Social Marketing. Gabriola Island, BC, Canada: New Society Publishers.

Morecroft, John D.W (1982), "A Critical Review of Diagraming Tools for Conceptualizing Feedback System Models," Dynamica, 8 (1), 20-9.

Morin, Edgar (2006), "Restricted Complexity, General Complexity," presented at the Colloquium "Intelligence de la complexité: épistémologie et pragmatique”, Cerisy-La-Salle, France, June 26, 2005. Translated from French by Carlos Gershenson (accessed on February 8, 2021). [available at http://cogprints.org/5217/1/Morin. pdf].

O’Donoghue, Paul (2017), ““‘'We Wondered, Would We Die as a Town?': How Westport was Regenerated", FORA, (accessed on June 7, 2021), [available at https://fora.ie/westport-town-mayoregeneration-3622103-Sep2017/].

Pappas, Ilias O. and Arch G. Woodside (2021), "Fuzzy-set Qualitative Comparative Analysis (fsQCA): Guidelines for Research Practice in Information Systems and Marketing," International Journal of Information Management, 58 (2021), 102310.

Patton, Michael Quinn (2011), Developmental Evaluation: Applying Complexity Concepts to Enhance Innovation and Use. New York, NY: The Guilford Press. 
Previte, Josephine and Nichola Robertson (2019), "A Continuum of Transformative Service Exchange: Insights for Service and Social Marketers," Journal of Services Marketing, 33 (6), 671-86.

Rau, Henrike, Michael Hynes, and Barbara Heisserer (2016), "Transport Policy and Governance in Turbulent Times: Evidence from Ireland," Case Studies on Transport Policy, 4 (2), 45-56.

Rees, David, Janet Stephenson, Debbie Hopkins, and Adam Doering (2017), "Exploring Stability and Change in Transport Systems: Combining Delphi and System Dynamics Approaches," Transportation, 44 (4), 789-805.

Reidy, Theresa (2018), "Power Monopoly: Central - Local Relations in Ireland," in From Here to Where?, Sean Healy and Brigid Reynolds, eds. Dublin, Ireland: Social Justice Ireland, 1-14.

Ricigliano, Robert (2012), Making Peace Last: A Toolbox for Sustainable Peacebuilding. Abingdon, Oxon, UK: Routledge.

Rundle-Thiele, Sharyn, Patricia David, Taylor Willmott, Bo Pang, Lynne Eagle, and Rachel Hay (2019), "Social Marketing Theory Development Goals: An Agenda to Drive Change," Journal of Marketing Management, 35 (1-2), 160-81.

Saunders, Mark, Philip Lewis, and Adrian Thornhill (2019, Research Methods for Business Students, 8th. Harlow, Essex, UK: Pearson Education Ltd., 318-23.

Saunders, Stephen Graham and V. Dao Truong (2019), "Social Marketing Interventions: Insights from a System Dynamics Simulation Model," Journal of Social Marketing, 9 (3), 329-42.

Singleton, Royce A. Jr., Bruce C. Straits, and Margaret Miller Straits (1993), Approaches to Social Research. New York, NY: Oxford University Press, Inc.

Smith, William A (2000), "There's a Lion in the Village: The Fight Over Individual Behavior Versus Social Context," Social Marketing Quarterly, 6 (3), 6-12.

Steinfield, Laurel and Diane Holt (2020), "Structures, Systems and Differences That Matter: Casting an Ecological-Intersectionality Perspective on Female Subsistence Farmers' Experiences of the Climate Crisis," Journal of Macromarketing, 40 (4), 563-82.
Sterman, John (2000), Business Dynamics: Systems Thinking and Modelling for a Complex World. Boston, MA: Irwin/ McGraw-Hill.

Sterman, John (2018), "System Dynamics at Sixty: The Path Forward," System Dynamics Review, 34 (1/2), 5-47.

Truong, Van Dao (2017), "Government-led Macro-Social Marketing Programs in Vietnam: Outcomes, Challenges, and Implications," Journal of Macromarketing, 37 (4), 409-25.

Wolstenholme, Eric F (1999), "Qualitative vs Quantitative Modelling: The Evolving Balance," The Journal of the Operational Research Society, 50 (4), 422-28.

Wooliscroft, Ben (2016), "Introduction to the Special Issue on Research Methodology in Macromarketing: Macromarketing Research; it's not Rocket Science... it's Much Harder," Journal of Macromarketing, 36 (1), 8-10.

Wooliscroft, Ben (2020), "Systems and Macro-Social Marketing: Researching Wicked Problems," in Macro-Social Marketing Insights: Systems Thinking for Wicked Problems, Ann-Marie Kennedy, ed. New York, NY: Routledge, 12-26.

Wooliscroft, Ben (2021), "Macromarketing and the Systems Imperative," Journal of Macromarketing, 41 (1), 116-23.

\section{Author Biographies}

Dmitry Brychkov, BA English, MA Desert studies, $\mathrm{PhD}$, is a postdoctoral researcher with the Applied Systems Thinking Group in the Whitaker Institute at the National University of Ireland, Galway.

Christine Domegan, BComm, MBS, $\mathrm{PhD}$, is a senior lecturer in Marketing in the J.E Cairnes School of Business and Economics. She is the head of the Applied Systems Thinking Group within the Whitaker Institute at the National University of Ireland, Galway.

Patricia McHugh, BComm, MBS, $\mathrm{PhD}$, is a lecturer in Marketing at the J.E Cairnes School of Business and a principle investigator with the Applied Systems Thinking Group within the Whitaker Institute at the National University of Ireland, Galway. 